\title{
Composition and nutritional evaluation of amino acids in Mimai qu rice wines
}

\author{
Kaizheng Zhang ${ }^{1 *}$, Wenchi Wu ${ }^{1,2}$, Wei Zou ${ }^{1}$, Zhenhui Kang ${ }^{1}$, Qin Yan ${ }^{1}$, and Yue Qin ${ }^{1}$ \\ ${ }^{1}$ Sichuan University of Science E Engineering, Zigong City, Sichuan Province, China; ${ }^{2}$ Chengdu Institute of Product \\ Quality Inspection Co. Ltd, Chengdu, China
}

*Corresponding Author: Kaizheng Zhang, Sichuan University of Science \& Engineering, Zigong City, Sichuan Province, China. Email: kai7766@126.com

Received: 25 January 2021; Accepted: 22 April 2021; Published: 11 May 2021

(c) 2021 Codon Publications

OPEN ACCESS (c) (우웅

PAPER

\begin{abstract}
An amino acid analyzer was used to detect free amino acids (FAA) in Mimai $Q u$ rice wines (SMW and DMW) and control wine samples (Chinese rice wine $[\mathrm{CRW}]$ and Japanese sake [JNS]). It was found that CRW had the highest total amino acid (TAA) content ( 2814 mg/L), followed by SMW ( $2509 \mathrm{mg} / \mathrm{L})$ and DMW $(\sim 1474 \mathrm{mg} / \mathrm{L})$, while JNS had the least $(\sim 917 \mathrm{mg} / \mathrm{L})$. Amino acid ratio coefficient method (SRCAA), linear regression method, cluster analysis (CA) and principal component analysis (PCA) were used for evaluating the nutritional value of amino acids in wine samples, giving similar results. SMW had the highest nutritional value, followed by CRW and DMW and JNS.
\end{abstract}

Keywords: brewed wine, cluster analysis, linear regression analysis, principal component analysis, ratio coefficient method

\section{Introduction}

Mimai $Q u$ rice wines, prepared from crushed wheat malt (25\%) and steamed rice (75\%) using the Japanese koji process with Aspergillus oryzae Su-16 and Aspergillus oryzae AOK139 as inoculum (China application patent No.: CN201810216324), is a novel fermentation starter (http://pss-system.cnipa.gov.cn/sipopublicsearch/portal/ uilogin-forwardLogin.shtml). As for Chinese rice wine (CRW), the brewing properties of Mimai $Q u$ are similar to those of traditional wheat $Q u$. However, Mimai $Q u$ rice wine is made from purified microbes, and the hygiene of the production environment and food safety are much higher than that of wheat $Q u$. Mature Mimai $Q u$ rice wine is white in color (the wheat $Q u$ of CRW shows yellow color) with a delicate fragrance that is distinct from the complex aroma of wheat $Q u$. Mimai $Q u$ rice wine is transparent, light yellow in color and has a fresh and elegant mild fruity flavor, but without the so-called "soy sauce flavor" of CRW (Wang and $\mathrm{Xu}, 2005$ ). Its taste and flavor are between those of CRW and Japanese sake (JNS). A small-scale tasting survey conducted in the
Sichuan Province of China revealed its popularity than CRW among young people.

Japanese Sake, a Japanese alcoholic beverage, is generally prepared from the polished Japonica rice and koji with an alcohol content of 13-17\% v/v (Sato and Kohsaka, 2017). It has a refreshing taste and fruity aroma, and its market is widely distributed in Japan, the United States, Southeast Asia and some European countries (Mimura et al., 2014). The production of JNS requires partial grinding of the outer layer of rice to produce "polished rice." The rate of polished rice refers to the ratio of the mass of polished rice to that of original mass. The lower the rate of polished rice, the lower the content of protein and lipid in rice, thereby making it more suitable for brewing high-quality sake such as Daiginjo (Okuda, 2019; Yamashita, 1997). CRW has originated in China and is one of the world's oldest alcoholic beverages with a history of thousands of years (Mcgovern et al., 2004). It is brewed using glutinous rice, wheat $Q u$ (fermentation starter) and water. CRW has a mellow and rich taste, and contains various nutrients such as amino acids, 
oligosaccharides, short peptides etc., and therefore is also called "liquid cake" (Wang, 1998). Currently, 90\% of CRW consumption is concentrated in eastern China, including Zhejiang Province, Jiangsu Province and Shanghai, which pose regional restrictions for aging consumer groups (Jiao et al., 2017; Xu et al., 2013). After the 2010s, because of lack of innovation in the production process of CRW, its taste and flavor are not considered attractive by the current young and middle-aged consumers, thus gradually losing these huge main consumer groups (Jiao et al., 2017). In 2018, two Mimai Qu rice wines (DMW and SMW) were creatively developed using Mimai $Q u$ and polished Japonica rice varieties as raw materials by combining the processing techniques of sake and CRW in our laboratory to attract young people and broaden the consumer groups and consumption areas of CRW.

Amino acids are basic components of protein, providing significant nutrition, and are divided into essential amino acids (EAA) and non-essential amino acids (NEAA) (Cui et al., 2014; Omar et al., 2017). Generally, men prefer to drink moderate-alcohol beverages, such as CRW, with an average intake of 1000-1500 mL/d (Yang, 2021), containing 3-5 g/d of free amino acids (FAA). Moreover, FAA is a non-negligible nutrition source, as it can be easily assimilated and utilized by the human body. Contents and composition of amino acids are important factors in the nutritional value of foods (González-Castro et al., 1997; Okada et al., 2017). Therefore, this study intended to detect the content and composition of FAA in Mimai $Q u$ rice wine, and assess its amino acid nutritional value using different analytical methods. This study would provide a theoretical basis for further analyzing the nutritional profiles of this novel rice wine.

\section{Materials and Methods}

\section{Materials}

Chinese Rice Wine (CRW): Traditional CRWs produced in the Shaoxing city of China were purchased from WalMart Supermarket, Zigong City, Sichuan Province. The raw materials included glutinous rice, wheat $Q u$ and water. The alcohol content of this wine was $13-16 \% \mathrm{v} / \mathrm{v}$, and the total sugar content was $20-30 \mathrm{~g} / \mathrm{L}$. The age of the wine was 3-5 years. In all, three CRW wine samples, such as Guyuelongshan, Kuaijishan and Tapai, were analyzed in this study.

Japanese Sake: Sakes were purchased from Japan. The raw materials included water, Yamadanishiki rice and rice koji, with a polishing ratio of $50-70 \%$. The alcohol content was $14-16 \% \mathrm{v} / \mathrm{v}$ and the total sugar content was 20-35 g/L. The age of sake was 1-5 years. Three sake wine samples were analyzed in this study: company A, B, and $C$ produced in the cities of Yamaguchiken, Kobe, and Kyoto of Japan, respectively.

Mimai $Q u$ rice wine (dry type), abbreviated as DMW, was brewed in 2018 with Mimai Qu rice and water as raw materials at a polishing ratio of $70 \%$. Brewing method: The rice was soaked for $45 \mathrm{~min}$ after polishing and then steamed, followed by spreading and cooling to $35-40^{\circ} \mathrm{C}$. Mimai $Q u$, equal to $12 \%$ of rice, and commercial mineral water at a volume equal to that of rice were added as raw materials. The initial temperature of the mash was controlled at $20-25^{\circ} \mathrm{C}$, and after $6 \mathrm{~h}$, lactic acid equivalent to $0.7 \%$ of the mass of mash was added to perform acidification. Saccharomyces cerevisiae (pre-activated into yeast mash) equivalent to $0.1 \%$ of raw material was then added and mixed evenly. Seeding mash was achieved after a day of culture. The feeding was carried out as per the threestep feeding method described in Table 1. After the third feeding, fermentation of DMW was commenced officially and completed in 20 days (Figure 1). DMW was light yellow and transparent in color, with a fresh and elegant flavor without the so-called "soy sauce flavor" of CRW. Additionally, it had a light fruity aroma. Its alcohol content was $16-18 \% \mathrm{v} / \mathrm{v}$ and the total sugar content was 6-9 g/L. The wine storage time was 1 year. Four DMW wine samples were analyzed in this study.

Mimai Qu rice wine (semi-sweet; SMW): The raw materials and brewing process were essentially the same as that for DMW, except that in the course of each feeding, 30\% of the brewed water was replaced by aged CRW (15\% v/v; total sugar content: $6 \mathrm{~g} / \mathrm{L})$. Therefore, SMW

Table 1. Three-step feeding method for DMW brewing.

\begin{tabular}{|c|c|c|c|c|c|}
\hline Ingredients & Seeding mash & First feeding & Second feeding & Third feeding & Total \\
\hline Rice (kg) & 50 & 100 & 200 & 400 & 750 \\
\hline Mimai Qu (kg) & 6 & 20 & 40 & 80 & 146 \\
\hline Water $(\mathrm{L})$ & 50 & 160 & 320 & 640 & 1170 \\
\hline Lactic acid (L) & 7.5 & 0 & 0 & 0 & 7.5 \\
\hline Yeast culture solution (L) & 5.5 & 0 & 0 & 0 & 5.5 \\
\hline
\end{tabular}




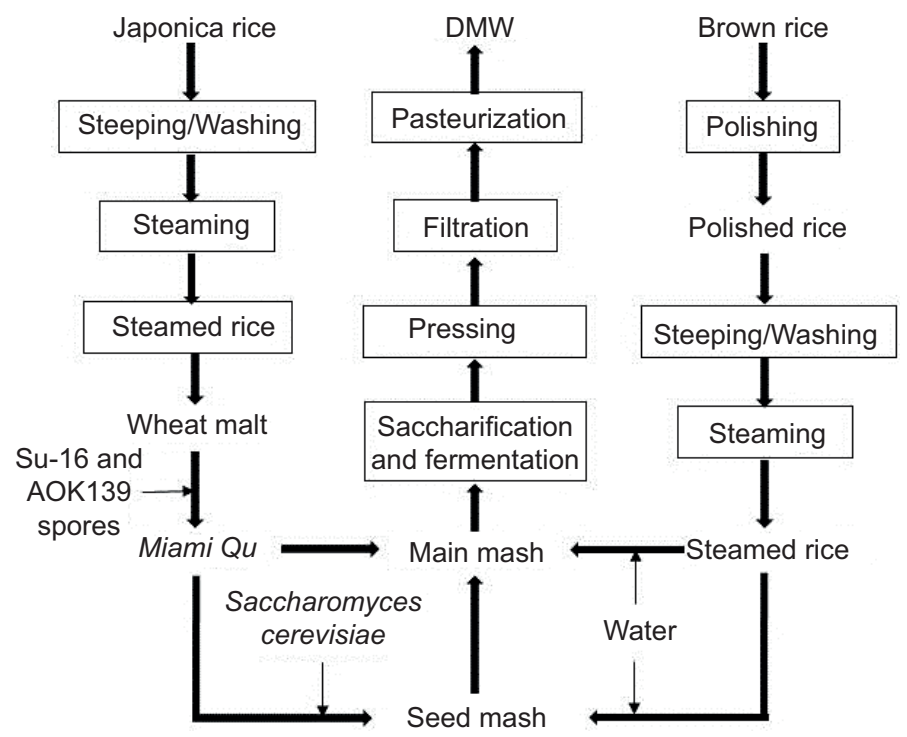

Figure 1. The brewing process of DMW (Mimai Qu rice wine, dry type).

was with a brewing characteristic of "wine made from wine" and contained more oligosaccharides with a semisweet taste. The alcohol content in SMW was 14-16\% v/v and the total sugar content was $40-60 \mathrm{~g} / \mathrm{L}$ with the storage age of 1 year. Four SMW wine samples were analyzed in this study.

\section{Methods}

\section{Amino acids determination method}

Free amino acids in the test sample were analyzed by L-8900 amino acid automatic analyzer (HITACHI, Japan), with a 53-min short program (including the time for washing and rinsing columns).

Wine sample pretreatment: After filtration, $40 \mathrm{~mL}$ of 10\% trichloroacetic acid (Sigma-Aldrich Trading Co. Ltd, Shanghai, China) was added to every $10 \mathrm{~mL}$ of wine sample to remove proteins, followed by centrifugation in a high-speed centrifuge at $5000 \mathrm{rpm}$ for $10 \mathrm{~min}$. The supernatant solution was dried thrice in an oven at $50^{\circ} \mathrm{C}$ to remove alcohol, after which $0.02 \mathrm{~mol} / \mathrm{L}$ of HCL (China National Sinopharm Chemical Reagent Co. Ltd., Shanghai, China) solution was added to a final volume of $10 \mathrm{~mL}$. After centrifugation, $1 \mathrm{~mL}$ of supernatant was taken and tested directly on the machine.

\section{Evaluation Methods for Amino Acid Nutrition}

\section{Amino acid ratio coefficient method}

The WHO/FAO meeting in 1973 pointed out that the amino acid composition of proteins in eggs and human milk is most suitable for absorption by human body and has high nutritional value. Therefore, the composition and content of EAA in eggs and human milk were used as templates to evaluate the amino acid ratio (RAA; Equation 1) and the ratio coefficient (RC; Equation 2) in foods to derive the score of ratio coefficient (SRC; Equation 3) of amino acids. This is called the score of ratio coefficient of amino acid (SRCAA) method, which is employed to evaluate the amino acid nutritional value of the food (FAO/WHO, 1973).

$$
\begin{gathered}
\text { RAA }=\frac{\text { EAA content of the food to be evaluated }}{\begin{array}{c}
\text { The corresponding EAA content } \\
\text { recommended by WHO } / \text { FAO }
\end{array}} \\
\text { RC }=\frac{\text { RAA }}{\text { Mean value of RAA }}, \\
\text { SRC }=100-(\mathrm{CV} \times 100),
\end{gathered}
$$

where $\mathrm{CV}$ is the standard deviation coefficient of RC. $\mathrm{CV}=\mathrm{RC}$ standard deviation/RC mean.

\section{Linear regression analysis}

Linear regression is a statistical analysis method that analyzes the strength of correlation between two or more sets of data. The correlation coefficient " $R$ " reflects the degree of correlation in the data. Linear regression analysis is able to investigate the degree of correlation between the content of seven types of EAA in wine samples and the recommended pattern of WHO/FAO through the $\mathrm{R}$-value. The larger the $\mathrm{R}$-value, the greater the degree of correlation and higher nutritional value of the wine sample (Zhang et al., 2017). 


\section{Cluster analysis and principal component analysis}

The score of ratio coefficient of amino acid and linear regression analysis methods were adopted to examine similarities between seven types of EAA in the wine samples and the WHO/FAO-recommended model, which provided a good evaluation parameter. However, the manual calculation workload of the data was large and no investigation was carried out on the proportion of EAA, namely EAA/TAA and EAA/NEAA. Therefore, for a more comprehensive evaluation of the nutritional value of amino acids in brewed wines, EAA/TAA and EAA/ NEAA were also included within the scope of investigation (the two indicators were 0.4 and 0.6 according to the WHO/FAO-recommended model). Cluster analysis (CA) and principal component analysis (PCA) were employed for analysis and evaluation of EAA/TAA and EAA/NEAA. Since software is used in evaluation, the amount of manual calculation is greatly reduced. CA (Euclidian distance) is a method for data classification analyzing the similarity of observed data and clusters data to optimal groups. Observations in each category are different, with some level of similarity. The system clustering method can cluster wine samples and the WHO/FAO-recommended model separately. The wine sample that was grouped with the recommended model first had higher similarity with the recommended model as well as higher nutritional value (Biglari et al., 2009). PCA is a factor analysis method that reduces the number of factors in a dataset into several major components and ensures that most of the information is retained. Using the load map of PCA enables one to identify the wine sample that is closer to the WHO/FAO-recommended model. In the coordinate load map, the wine sample that is closer to the WHO/FAO-recommended model point has a greater nutritional value (Shin et al., 2010).

\section{Data Analysis}

All analyses were performed in triplicate. All statistical analyses were accomplished using DPS Statistical Software for Windows, version 15.10 (DPS 15.10, Hangzhou Rui Feng Information Technology Co. Ltd., Zhejiang, China) (Tang and Zhang, 2013). Significant differences were analyzed by Duncon's analysis of variance with $P<0.05$.

\section{Results and Discussion}

\section{Amino acids and their contents in the tested wine samples}

Table 2 lists 17 FAAs found in wine samples (Tryptophan was degraded at low $\mathrm{pH}$ and was not detected). The result indicated that the value for each type of wine was the mean of three to four samples, which could reduce the analysis and table width.

Apart for methionine (Met) that was not detected in JNS and DMW, other 16 amino acids were present in all wine samples. As shown in Table 2, among the tested samples, the highest TAA (2814.4 mg/L) was found in CRW. TAA in SMW was the second highest at $2509.8 \mathrm{mg} / \mathrm{L}$, while DMW had a TAA content of $1474.1 \mathrm{mg} / \mathrm{L}$. The lowest TAA was found in JNS at $916.5 \mathrm{mg} / \mathrm{L}(P<0.05)$. The most abundant amino acid was proline (Pro), followed by alanine (Ala) and asparagine (Asp). The most abundant amino acid found in JNS was arginine (Arg). The amino acids that ranked second and third highest were Ala and Asp, respectively. Ala had the highest content in SMW, followed by Asp and leucine (Leu) (Pro). The highest amino acid content in DMW was that of Pro, with Ala and Asp ranking second and third highest, respectively $(P<0.05)$. CRW uses traditional wheat $Q u$ as a starter with a protein content of about $8-11 \%$ (Ye et al., 2018; Zhang et al., 2019a), which is higher than that of rice. Moreover, since rice is not polished, its protein content is higher than that of polished rice. Therefore, more protein was decomposed or hydrolyzed into amino acids by microorganisms under acidic conditions during the fermentation process, resulting in a higher TAA in CRW. Rice koji is used as a starter to produce JNS, which has a lower protein content than wheat koji. When the polishing ratio reached $50 \%$, the amount of external protein was greatly reduced, resulting in a lower TAA content in brewed sake to only one-third of CRW. Since some wheat was included in both SMW and DMW koji, the TAA in these wines was higher than that in JNS but lower than that in CRW. In the brewing process, rice wine partially replaced brewing water, which also added some amino acids, resulting in higher TAA in SMW when compared with DMW.

Zhang et al. (2017) measured the amino acid content of hulless barley Zajiu using the automatic amino acid analyzer, and found that the TAA content in traditional Zajiu was $2875 \mathrm{mg} / \mathrm{L}$, which was equivalent to SMW. The EAA/TAA of SMW was $33.84 \%$, about $10 \%$ lower than traditional Zajiu. This may be due to the raw material for Zajiu being hulless barley, while that for the wine samples in this study were mainly rice and a small amount of wheat. Difference in brewing process may also contribute to this variation (Zhang et al., 2019b).

Luo et al. (2017) determined the amino acid content of beer sold in Lanzhou, China, by capillary electrophoresis. It was found that the total amount of amino acids in beer was about 260-370 mg/L. Kabelová et al. (2008) compared the amino acid content found in Czech Republic beer and foreign brand beer by the HPLC method and found that the TAA content of Czech Republic beer was 
Table 2. Individual amino acids in the tested wine samples ( $\mathrm{mg} / \mathrm{L})$.

\begin{tabular}{|c|c|c|c|c|}
\hline FAA & $\operatorname{SMW}(n=4)$ & DMW $(n=4)$ & JNS $(n=3)$ & CRW $(n=3)$ \\
\hline Thr & $90.2 \pm 7.8^{\mathrm{a}}$ & $55.4 \pm 6.1^{b}$ & $28.8 \pm 6.6^{c}$ & $94.2 \pm 11.2^{\mathrm{a}}$ \\
\hline Val & $158.6 \pm 13.3^{a}$ & $68.5 \pm 7.4^{c}$ & $38.4 \pm 9.7^{d}$ & $116.2 \pm 16.6^{b}$ \\
\hline Met & $20.4 \pm 3.6^{b}$ & nd & nd & $28.4 \pm 5.5^{\mathrm{a}}$ \\
\hline lle & $105.4 \pm 9.2^{\mathrm{a}}$ & $45.2 \pm 6.9^{b}$ & $24.1 \pm 5.2^{c}$ & $91.1 \pm 12.6^{a}$ \\
\hline Leu & $257.1 \pm 19.3^{a}$ & $110.7 \pm 9.4^{b}$ & $71.9 \pm 11.2^{c}$ & $240.1 \pm 28.7^{a}$ \\
\hline Phe & $89.4 \pm 7.7^{b}$ & $60.7 \pm 7.3^{c}$ & $37.6 \pm 6.3^{d}$ & $116.3 \pm 15.7^{\mathrm{a}}$ \\
\hline Lys & $128.4 \pm 16.1^{\mathrm{a}}$ & $72.9 \pm 8.2^{b}$ & $31.2 \pm 6.6^{c}$ & $124.0 \pm 18.2^{\mathrm{a}}$ \\
\hline Asp & $317.3 \pm 19.6^{\mathrm{a}}$ & $178.9 \pm 20.2^{b}$ & $108.3 \pm 14.7^{c}$ & $282.5 \pm 32.9^{\mathrm{a}}$ \\
\hline Ser & $143.7 \pm 9.7^{b}$ & $88.1 \pm 6.6^{c}$ & $48.6 \pm 8.5^{d}$ & $176.4 \pm 22.6^{\mathrm{a}}$ \\
\hline Glu & $102.2 \pm 11.5^{b}$ & $53.9 \pm 4.1^{c}$ & $29.2 \pm 6.3^{d}$ & $167.7 \pm 21.4^{\mathrm{a}}$ \\
\hline Gly & $225.2 \pm 16.1^{\mathrm{a}}$ & $139.8 \pm 17.2^{b}$ & $73.8 \pm 11.1^{c}$ & $208.9 \pm 27.2^{\mathrm{a}}$ \\
\hline Ala & $355.0 \pm 23.8^{a}$ & $187.6 \pm 24.4^{b}$ & $112.2 \pm 24.0^{c}$ & $325.6 \pm 41.3^{\mathrm{a}}$ \\
\hline Cys & $19.1 \pm 2.4^{a}$ & $9.1 \pm 1.1^{b}$ & $3.8 \pm 1.1^{c}$ & $4.7 \pm 1.6^{c}$ \\
\hline Tyr & $155.0 \pm 16.2^{\mathrm{a}}$ & $124.0 \pm 11.5^{b}$ & $83.7 \pm 12.5^{c}$ & $150.3 \pm 19.6^{a}$ \\
\hline His & $70.9 \pm 8.8^{a}$ & $36.4 \pm 3.7^{b}$ & $21.7 \pm 4.3^{c}$ & $62.5 \pm 11.3^{\mathrm{a}}$ \\
\hline $\operatorname{Arg}$ & $14.8 \pm 2.2^{\mathrm{d}}$ & $58.5 \pm 7.4^{c}$ & $124.7 \pm 18.0^{b}$ & $231.7 \pm 17.2^{\mathrm{a}}$ \\
\hline Pro & $257.1 \pm 22.8^{b}$ & $184.3 \pm 16.6^{c}$ & $78.6 \pm 11.6^{d}$ & $393.8 \pm 27.8^{a}$ \\
\hline TAA & $2509.8 \pm 19.4^{b}$ & $1474.1 \pm 17.7^{c}$ & $916.5 \pm 13.7^{d}$ & $2814.4 \pm 17.3^{\mathrm{a}}$ \\
\hline EAA & $849.5 \pm 7.5^{\mathrm{a}}$ & $413.5 \pm 3.2^{b}$ & $231.9 \pm 4.4^{c}$ & $810.3 \pm 9.6^{a}$ \\
\hline NEAA & $1660.3 \pm 12.4^{b}$ & $1060.6 \pm 9.7^{c}$ & $684.6 \pm 4.5^{\mathrm{d}}$ & $2004.1 \pm 11.2^{a}$ \\
\hline EAA/TAA (\%) & $33.8 \pm 2.2^{\mathrm{a}}$ & $28.0 \pm 1.8^{b}$ & $25.3 \pm 1.4^{\mathrm{bc}}$ & $28.8 \pm 2.2^{b}$ \\
\hline EAA/NEAA (\%) & $51.2 \pm 3.3^{\mathrm{a}}$ & $39.0 \pm 3.4^{b}$ & $33.9 \pm 2.4^{\mathrm{bc}}$ & $40.4 \pm 3.9^{b}$ \\
\hline
\end{tabular}

FAA: free amino acid; SMW: Mimai Qu rice wine (semi-sweet); DMW: Mimai Qu rice wine (dry type); JNS: Japanese sake; CRW: Chinese rice wine; TAA: total amino acids; EAA: essential amino acids; NEAA: non-essential amino acids; nd: not detected; Thr: threonine; Val: valine; Met: methionine; Ile: isoleucine; Leu: leucine; Phe: phenylalanine; Lys: lysine; Asp: asparagine; Ser: serine; Glu: glutamine; Gly: glycine; Ala: alanine; Cys: cysteine;

Tyr: tyrosine; His: histidine; Arg: arginine; Pro: proline.

higher than that of foreign beer $(\sim 450 \mathrm{mg} / \mathrm{L}$ vs $\sim 257$ $\mathrm{mg} / \mathrm{L}$ ). This result was consistent with the results of Redruello et al. (2017). The amino acid content in beer was much lower than that in the wine samples used in this study. This may be due to the brewing process of beer, as the amount of water added was four to seven times of the mass of raw materials, while for the Mimai $\mathrm{Qu}$ wine or JNS production in this study, the amount of water did not exceed twice the mass of raw materials.

\section{Results of SRCAA method}

The nutritional value of amino acids in brewed wine is reflected by the proportion of TAA and EAA. A better estimate is the degree of compatibility of EAA and the standard pattern of amino acids most easily absorbed by the human body. WHO/FAO pointed out that when cysteine and tyrosine (Tyr) are abundant in diet, they can partially replace methionine and phenylalanine (Phe). Therefore, phenylalanine and tyrosine, and methionine and cysteine (Cys) were consolidated in the SRCAA method. Based on this, the optimal ratio of EAA in food was proposed as follows: threonine:cystine + methionine:valine:isoleucine:leucine:phenylalanine + tyrosine: lysine:tryptophan = 8:7:10:8:14:12:11:2 (FAO/WHO, 1973). When the ratio of EAA in food is close to this ratio, it is more easily absorbed by the body, with higher nutritional value. As shown in Table 3, among the wine samples, SMW presented the smallest RC variation coefficient with the highest SRC ( 66) and higher nutritional value, followed by CRW ( 60) and DMW ( 46). The SRC value of JNS $(\sim 33)$ was only half of that for SMW, showing the lowest nutritional value $(P<0.05)$. The first limited amino acids in the wine samples were methionine + cystine.

\section{Evaluation results based on linear regression method}

The R-value was used to establish the correlation between contents of seven EAA in the wine samples and the recommended pattern of WHO/FAO. The R-value of SMW was the largest (0.938), indicating that its EAA is closest to the WHO/FAO-recommended model, with higher nutritional value. The R-value of CRW ranked 
Table 3. RAA, RC and SRC of the tested wine samples from SRCAA methods.

\begin{tabular}{|c|c|c|c|c|c|c|c|c|}
\hline \multirow{2}{*}{$\begin{array}{l}\text { Wine sample } \\
\text { Indicator }\end{array}$} & \multicolumn{2}{|c|}{ SMW } & \multicolumn{2}{|c|}{ DMW } & \multicolumn{2}{|c|}{ JNS } & \multicolumn{2}{|c|}{ CRW } \\
\hline & RAA & $\mathrm{RC}$ & RAA & $\mathrm{RC}$ & RAA & $\mathrm{RC}$ & RAA & $\mathrm{RC}$ \\
\hline Thr & 0.564 & 0.819 & 0.347 & 0.958 & 0.180 & 0.866 & 0.589 & 0.914 \\
\hline Val & 0.793 & 1.152 & 0.343 & 0.947 & 0.192 & 0.924 & 0.581 & 0.902 \\
\hline Lle & 0.657 & 0.957 & 0.283 & 0.781 & 0.151 & 0.726 & 0.570 & 0.884 \\
\hline Leu & 0.918 & 1.334 & 0.395 & 1.092 & 0.257 & 1.236 & 0.858 & 1.332 \\
\hline Lys & 0.584 & 0.848 & 0.331 & 0.916 & 0.142 & 0.683 & 0.564 & 0.876 \\
\hline Met + Cys & 0.282 & $0.410^{*}$ & 0.065 & $0.180^{*}$ & 0.027 & $0.131^{*}$ & 0.237 & $0.367^{*}$ \\
\hline Phe + Tyr & 1.019 & 1.480 & 0.770 & 2.127 & 0.505 & 2.434 & 1.111 & 1.725 \\
\hline SRC & \multicolumn{2}{|c|}{$66.818^{\mathrm{a}}$} & \multicolumn{2}{|c|}{$46.409^{c}$} & \multicolumn{2}{|c|}{$33.807^{d}$} & \multicolumn{2}{|c|}{$60.692^{b}$} \\
\hline
\end{tabular}

RAA: amino acid ratio; RC: ratio coefficient of amino acids; SRC: the most limiting amino acids of corresponding wine sample; SMW: Mimai Qu rice wine (semi-sweet); DMW: Mimai Qu rice wine (dry type); JNS: Japanese sake; CRW: Chinese rice wine.

*Mean values within rows without a common superscript lowercase letter indicate significant differences $(P<0.05)$.

second (0.900), while no significant difference was observed between R-values of CRW and SMW $(P<0.05)$. The ranked order of the other two wine samples with respect to the R-value was DMW (0.775) and JNS (0.752) $(P<0.05)$. These results were consistent with the SRCAA results except for the significant difference between CRW and SMW in the SRCAA method $(P<0.05)$.

\section{Cluster analysis and principal component analysis evaluation results}

Cluster analysis and PCA are the analytical tools in current statistical analysis to study the hidden connections between samples with unclear data and grouping relationships (Granato et al., 2018). It can solve many problems of data analysis involving food science by in-depth mining and data analysis (Brown, 2017). The CA is an exploratory data analysis tool that investigates the similarity of data's potential structure and then divides them into groups (Govender and Sivakumar, 2019). The PCA reduces multiple variables in the sample into several main components through dimensionality reduction, with most of the information being retained for data analysis. Based on the results of CA analysis of amino acid data, the wine samples and the WHO/FAO-recommended model were divided into two categories (Figure 2). The first category consisted of SMW, CRW and WHO/FAOrecommended model, while the second category included JNS and DMW. The first category could be divided into two sub-categories: SMW and CRW in one group, and WHO/FAO-recommended model in another group. It was concluded that the amino acid nutritional values of SMW and CRW were similar and were initially grouped into one class with the WHO/FAO-recommended model, indicating that the amino acid composition of the

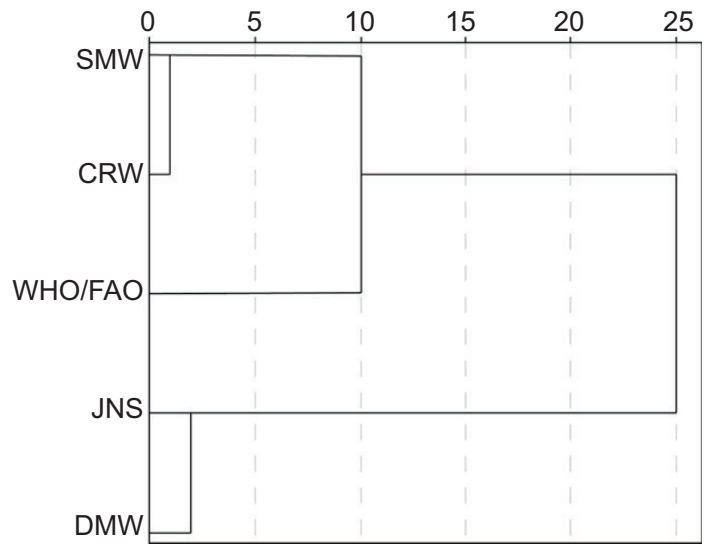

Figure 2. Cluster analysis results of the tested wine samples based on their amino acid data. WHO/FAO: the WHO/ FAO-recommended amino acid model; JNS: Japanese sake; CRW: Chinese rice wine; SMW: Mimai Qu rice wine (semisweet); DMW: Mimai Qu rice wine (dry type).

two wine samples was closer to that of the WHO/FAOrecommended model. Since the amino acid nutritional values of DMW and JNS were similar, they were placed in the same group, and were quite different from the WHO/ FAO-recommended model.

Based on the amino acid test data and via PCA, it was found that PC1 and PC2 explained more than 90\% of the total variance. Therefore, PC1 and PC2 were selected for further investigation. Among the wine samples, SMW was the most related sample to the WHO/ FAO-recommended model (Figure 3), with a significant coefficient of 0.001 , followed by CRW with a significant coefficient of 0.002. DMW ranked third (with a significant coefficient of 0.006), and JNS ranked last (with a 


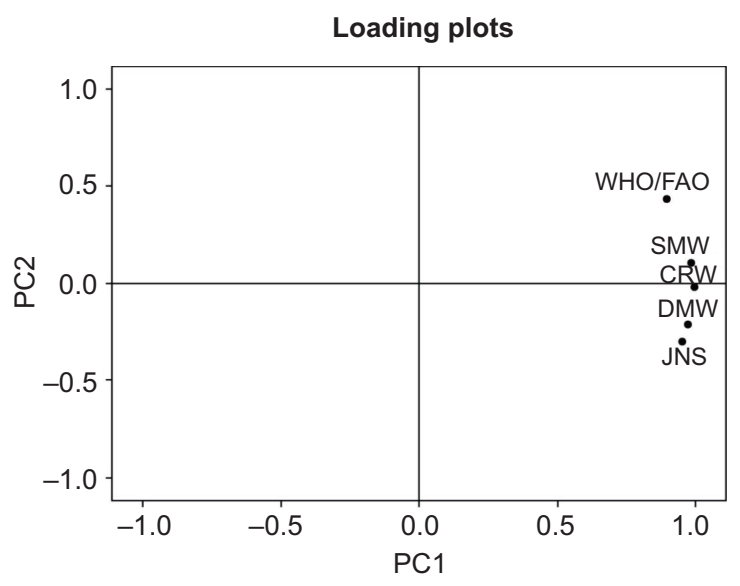

Figure 3. PC1 vs PC2 plots of principle component analysis based on the amino acid data of the tested wine samples. SMW: Mimai Qu rice wine (semi-sweet); DMW: Mimai Qu rice wine (dry type); JNS: Japanese sake; CRW: Chinese rice wine.

significant coefficient of 0.013). In other words, SMW had the highest nutritional value of amino acids, followed by CRW, DMW and JNS. It can also be seen from Figure 3 that in $\mathrm{PC} 1$, all samples were positively correlated with WHO/FAO-recommended model. In PC2, DMW and JNS were negatively associated with WHO/ FAO-recommended model, and CRW had a slight negative correlation with WHO/FAO-recommended model (correlation coefficient was -0.017). SMW was positively correlated with WHO/FAO-recommended model. The point on the load map corresponds to the vector projection of that sample on PC1 and PC2.

The above results showed that when two indicators EAA/ TAA and EAA/NEAA were considered, the results of CA and PCA were consistent with those of SRCAA and linear regression. Since the indicators were more comprehensive, the conclusions from CA and PCA analysis were more persuasive.

\section{Conclusion}

An amino acid analyzer was employed to detect FAAs in brewed wines. Simultaneously, the nutritional value of amino acids was evaluated by multiple methods. The results showed that TAA, EAA and NEAA contents were highest in CRW, while the proportion of EAA was lower than that found in SMW. The amino acid content and EAA ratio in DMW ranked third, while JNS ranked last. Considering nutritional evaluation by different methods, the results obtained by the SRCAA method, linear regression method, and CA and PCA analysis were consistent with one another. The EAA composition of SMW was closest to the WHO/FAO-recommended model, indicating the highest nutritional value of amino acids in SMW, followed by CRW, DMW and JNS.

\section{Disclosure Statement}

Authors have no potential conflicts of interest.

\section{Acknowledgments}

This work was supported by the Sci-Tech Programme of the Sichuan Province of China (No. 2020JDRC0097); the R\&D Programme of the Neijiang City of Sichuan Province of China (No. 2020KJFH008) and Liquor Making Biotechnology and Application Key Laboratory of the Sichuan Province of China (NJ2016-02).

\section{References}

Biglari, F., Alkarkhi, A.F.M. and Easa, A.M., 2009. Cluster analysis of antioxidant compounds in dates (phoenix dactylifera): effect of long-term cold storage. Food Chem. 112(4): 998-1001. https:// doi.org/10.1016/j.foodchem.2008.06.063

Brown, S., 2017. The chemometrics revolution re-examined. J Chemomet. 31(1): 1-23. https://doi.org/10.1002/cem.2864.

Cui, Y., Jiang, Z., Sun, J.Y., Yu, J., Li, M.H. and Li, M.J., 2014. Enantiomeric purity determination of (L)-amino acids with pre-column derivatization and chiral stationary phase: development and validation of the method. Food Chem. 158: 401-407. https://doi.org/10.1016/j.foodchem.2014.02.133

FAO/WHO, 1973. Energy and protein requirements. Report of a Joint FAO/WHO Adhoc Expert Committee. FAO Nutritional Meeting Report Series No. 52, Technical Report Series No. 522 Food and Agriculture Organization of the United Nation, Rome, Italy.

González-Castro, M.J., López-Hernández, J., Simal-Lozano, J. and Oruna-Concha, M.J., 1997. Determination of amino acids in green beans by derivatization with phenylisothiocianate and high-performance liquid chromatography with ultraviolet detection. J Chromat Sci. 35: 181-185. https://doi.org/10.1093/ chromsci/35.4.181

Govender, P. and Sivakumar, V., 2019. Application of k-means and hierarchical clustering techniques for analysis of air pollution: a review (1980-2019). Atmos Pollution Res. 11(1): 40-56. https:// doi.org/10.1016/j.apr.2019.09.009

Granato, D., Santos, J.S., Escher, G.B., Ferreira, B.L. and Maggio, R.M., 2018. Use of principal component analysis (PCA) and hierarchical cluster analysis (HCA) for multivariate association between bioactive compounds and functional properties in foods: a critical perspective. Trends Food Sci Technol. 72: 83-90. https://doi.org/10.1016/j.tifs.2017.12.006

Jiao, A.Q., Xu, X.M. and Jin, Z.Y., 2017. Research progress on the brewing techniques of new-type rice wine. Food Chem. 215: 508-515. https://doi.org/10.1016/j.foodchem.2016.08.014 
Kabelová, I., Dvořáková, M., Čížková, H., Dostálek, P. and Melzoch, K., 2008. Determination of free amino acids in beers: a comparison of Czech and foreign brands. J Food Comp Anal. 21(8): 736-741. https://doi.org/10.1016/j.jfca.2008.06.007

Luo, T., Ke, J., Xie, Y.F. and Dong, Y.M., 2017. Determination of underivatized amino acids to evaluate quality of beer by capillary electrophoresis with online sweeping technique. J Food Drug Anal. 25(4): 789-797. https://doi.org/10.1016/j.jfda.2017.03.003

McGovern, P.E., Zhang, J.Z., Tang, J.G., Zhang, Z.Q., Hall, G.R. and Moreau, R.A., 2004. Fermented beverages of pre- and proto-historic China. Proc Nat Acad Sci USA. 101(51): 17593-17598. https://doi.org/10.1073/pnas.0407921102

Mimura, N., Isogai, A., Iwashita, K., Bamba, T. and Fukusaki, E., 2014. Gas chromatography/mass spectrometry-based component profiling and quality prediction for Japanese sake. J Biosci Bioeng. 118(4): 406-414. https://doi.org/10.1016/j. jbiosc.2014.04.006

Okada, C., Iso, H., Ishihara, J., Maruyama, K., Sawada, N. and Tsugane, S., 2017. Validity and reliability of a self-administered food frequency questionnaire for the JPHC study: the assessment of amino acid intake. J Epidemiol. 27(5): 242-247. https:// doi.org/10.1016/j.je.2016.06.003

Okuda, M., 2019. Rice used for Japanese sake making. Biosci, Biotechnol Biochem. 83(8): 1-14. https://doi.org/10.1080/0916 8451.2019.1574552

Omar, M.M.A., Elbashir, A.A. and Schmitz, O.J., 2017. Capillary electrophoresis method with UV-detection for analysis of free amino acids concentrations in food. Food Chem 214: 300-307. https://doi.org/10.1016/j.foodchem.2016.07.060

Redruello, B., Ladero, V., del Rio, B., Fernández, M., Martin, M.C. and Alvarez, M.A., 2017. A UHPLC method for the simultaneous analysis of biogenic amines, amino acids and ammonium ions in beer. Food Chem 217: 117-124. https://doi.org/10.1016/j. foodchem.2016.08.040

Sato, J. and Kohsaka, R., 2017. Japanese sake, and evolution of technology: a comparative view with wine and its implications for regional branding and tourism. J Ethnic Foods 4(2): 88-93. https://doi.org/10.1016/j.jef.2017.05.005

Shin, E.C., Craft, B.D., Pegg, R.B., Phillips, R.D. and Eitenmiller, R.R., 2010. Chemometric approach to fatty acid profiles in runner-type peanut cultivars by principal component analysis (PCA). Food Chem. 119(3): 1262-1270. https://doi. org/10.1016/j.foodchem.2009.07.058

Tang, Q.Y. and Zhang, C.X., 2012. Data processing system (DPS) software with experimental design, statistical analysis and data mining developed for use in entomological research. Insect Sci. 20: 254-260. https://doi.org/10.1111/j.1744-7917.2012.01519.x

Wang, J.G., 1998. The nutritional value and healthcare function of Chinese Rice Wine. China Brewing 6: 34-40 (in Chinese).

Wang, J.G. and Xu, L., 2005. Features of millet wine and its prospects. Jiangsu Condim Subsidiary Food. 22(6): 5-9.

Xu, Y., Chen, S., Wang, D. and Zhao, G.A., 2013. Research progress in the producing technology of Chinese yellow rice wine. Liquor-Making Sci Technol. 12: 1-8 (in Chinese).

Yamashita, M., 1997. The appearance on earth and development of cereal Koji and cereal alcholic beverages. J Soc Brewing Japan. 92(5): 310-321. https://doi.org/10.6013/ jbrewsocjapan1988.92.310

Yang, X., 2021. Marketing strategy analysis model of Huangjiu enterprises based on SWOT. Liquor-Making Sci Technol. 2: 123-127 (in Chinese).

Ye, D.D., Sun, L.J., Zou, B.R., Zhang, Q., Tan, W.Y. and Che, W.K., 2018. Non-destructive prediction of protein content in wheat using NIRS. Spectrochimica Acta Mol Biomol Spectro. 189: 463-472. https://doi.org/10.1016/j.saa.2017.08.055

Zhang, K.Z., Li, Q., Wu, W.C., Yang, J.G. and Zou, W., 2019a. Wheat $\mathrm{Qu}$ and its production technology, microbiota, flavor, and metabolites. J Food Sci. 84(9): 2373-2386. https://doi. org/10.1111/1750-3841.14768

Zhang, K.Z., Pan, Y.F., Zou, W., Zhou, L.H., Wu, Z.Y. and Zhang, W.X., 2017. Nutritive assessment of amino acids for three Chinese Zajius produced from hull-less barley. J Inst Brewing. 123(4): 587-593. https://doi.org/10.1002/jib.464

Zhang, K.Z., Yang, J.G., Qiao, Z.W., Cao, X.Z., Luo, Q.C. and Zhao, J.S., 2019b. Assessment of $\beta$-glucans, phenols, flavor and volatile profiles of hulless barley wine originating from highland areas of China. Food Chem. 293: 32-40. https://doi. org/10.1016/j.foodchem.2019.04.053 